\title{
Peer Pressure and Family Smoking Habits Influence Smoking Uptake in Teenage Boys Attending School: Multilevel Modeling of Survey Data
}

\author{
Shafquat Rozi1,2*, Sadia Mahmud33, Gillian Lancaster1, Nida Zahid² \\ ${ }^{1}$ Department of Mathematics and Statistics, Lancaster University, Lancashire, UK \\ ${ }^{2}$ Department of Community Health Sciences, Aga Khan University, Karachi, Pakistan \\ ${ }^{3}$ Department of Paediatrics \& Child Health, Aga Khan University, Karachi, Pakistan \\ Email: ‘shafquat.rozi@aku.edu,mahmud_sadia@yahoo.com,g.lancaster@lancaster.ac.uk, \\ nida.zahid@aku.edu
}

Received 29 March 2016; accepted 7 August 2016; published 10 August 2016

Copyright (C) 2016 by authors and Scientific Research Publishing Inc. This work is licensed under the Creative Commons Attribution International License (CC BY). http://creativecommons.org/licenses/by/4.0/

\section{(c) (i) Open Access}

\begin{abstract}
Introduction: Among young teens, about one in five smokes worldwide. Adolescents spend a considerable amount of their time in school, and the school environment is therefore important for child health practices and outcomes. Objectives: We aimed to investigate the impact on smoking behavior of the school environment and the personal characteristics of male teenage students attending schools in Pakistan, taking into account the survey sampling structure. Methods: A twostage cluster sampling with stratification was employed, and we interviewed 772 male secondary school students. We adopted random effect and generalizing estimating equation models. Results: Peer pressure in particular had a strong influence on adolescents smoking; those whose friends smoked were up to 6 times more likely to smoke. Family smoking was also significantly associated with adolescents smoking, but those students whose mother was educated were $50 \%$ less likely to smoke. The fitted random effect model indicated that the between school variability was significant (p-value $<0.01$ ), indicating differences in smoking habits between schools. A random coefficient model showed that variability among schools was not significantly different for public and private schools. Conclusion: Public health campaigns for smoking cessation should target not only the individual but also the families of adolescents attending schools.
\end{abstract}

\footnotetext{
${ }^{*}$ Corresponding author.
}

How to cite this paper: Rozi, S., Mahmud, S., Lancaster, G. and Zahid, N. (2016) Peer Pressure and Family Smoking Habits Influence Smoking Uptake in Teenage Boys Attending School: Multilevel Modeling of Survey Data. Open Journal of Epidemiology, 6, 167-172. http://dx.doi.org/10.4236/ojepi.2016.63018 
Keywords

Teenage Smoking, Multilevel Model, Binary Outcome, Public \& Private Schools

\section{Introduction}

Tobacco is one of the greatest public health threats of modern times. It utilizes a substantial number of resources of the health care system of Pakistan both for treatment and for prevention [1]. The World Health Organization (WHO) currently estimates 5.4 million deaths every year due to tobacco use [1]. In the 21st century the estimated tobacco deaths will go up to one billion [1]. If urgent action is not taken it is expected that by 2030, there will be more than 8 million tobacco deaths every year of which more than $80 \%$ of tobacco deaths will occur in the developing countries [1].

Unfortunately funding for tobacco control is less than that for HIV/AIDS although tobacco kills far more people; therefore more funding is required for its prevention [2]. Till date only 27 countries have made an attempt to control tobacco usage by imposing tax rates of more than $75 \%$ on the retail price of tobacco [3]. However, the dilemma is that the epidemic is shifting towards the developing countries and it is predicted that $80 \%$ of tobacco-related deaths within a few decades will occur in the developing countries [1]. This devastating shift to the developing countries is due to the fact that the global tobacco industry is targeting young adults. Fifty five percent of households in Pakistan have at least one individual who smokes tobacco [4]. However there are no data available to measure the expenditure for treating diseases caused by tobacco in Pakistan. WHO estimates that currently worldwide 150 million adolescents are using tobacco [5]. Recent reviews conclude that the school environment has an influence on the behavior of the youth, their indulgence into alcohol, drug use and crime [6]. School plays a very crucial role in a child's development; therefore it is observed that mostly the smoking prevention programs are school based [7]. However, there is dearth of information about the influence of school environment on the adolescent smoking behavior. Substantial research has been done addressing the factors associated with adolescent smoking at individual level but to the best of our knowledge there is scarcity of data reporting the influence of school environment on adolescent smoking behavior.

Moreover, majority of epidemiological studies addressing health and smoking issues are survey-based which are carried out, either in the communities, in clinics, in hospitals or in schools. For conducting studies at such setting, survey is not sufficient in fact that there is a need of multi-stage sampling strategy that would incur a hierarchical structure.

It is observed that if clustering effect is ignored during the analysis stage and it is performed using individuals as the unit of analysis, the lower standard errors and p-values obtained from the individual level analysis will be incorrect, and can result in misleading inferences and conclusions regarding the significance of different factors [8]. Hence, the multilevel modeling approach indicates that variation in smoking prevalence between schools is not only due to differences in pupils' composition at the individual level, but also due to social and environmental effects at the school level [9].

There was a Survey on Teenage Smoking in Schools in Pakistan (STSSP) conducted and the objective of this study was to estimate the prevalence of, and to identify factors associated with, the smoking status of school going male adolescents in Karachi, Pakistan [10] [11]. In this study the investigators employed a two-stage cluster sampling strategy with stratification based on school type (public and private) to select students nested within schools (clusters). They conducted ordinary logistic regression analysis to identify factors associated with the smoking status of school going male adolescents [10] [11]; however, they did not take into account the multilevel nature of the data in their analysis which led to lower standard errors and the p-values obtained from this individual level analysis were misleading resulting in ambiguous inferences and conclusions.

Therefore the aim of this study was to identify the factors that may influence the uptake of smoking in male adolescents attending schools in Karachi, Pakistan. We took into account the multilevel structure of the survey sampling design and to address this we performed a multilevel random effect logistic regression model and GEE.

\section{Methods}

This was a school based cross-sectional study that was conducted in 3 Towns of Karachi i.e. Gadap Town, Bin 
Qasim Town and Malir Town. Two staged cluster sampling stratified by school type was employed to select schools and students. We recruited and interviewed 772 boys 431 from 15 public and 341 from 11 private of Karachi, Pakistan [10]. This study is a part of our original project "Prevalence and factors associated with smoking among school going adolescents in Karachi, Pakistan” whose primary objective was to estimate the prevalence and evaluate factors associated with smoking among school going teenage boys. Thus the sample size $(n=772)$ for our current study was achieved on the basis of our primary study and the details for the sample size estimation are given elsewhere [10].

Written consent was taken from individual school authorities for interviewing their students. The questionnaire included questions on socio-demographic factors, including age, ethnicity, religion, highest level of parental education, occupation of parents (proxy indicators for socio-economic status), smoking history of family and friends, number of siblings and place of residence, smoking behavior of the student, and the age and particular reasons for initiation of smoking. We also asked the students about the frequency of smoking [10]. The binary outcome variable, current smoking status (smoker or non-smoker), was assessed based on self-reported 30 days prevalence of cigarette smoking (that is whether or not the subject had smoked a cigarette in the past 30 days) [12].

\section{Statistical Analysis}

Since both individual and school level factors associated with smoking status of adolescents were analyzed, multilevel modeling and GEE were applied. We compared our results with an ordinary logistic regression model, to highlight the differences in interpretation that an inappropriately specified model can make. We also developed a random coefficient model to assess if the variability between schools was different for public and private schools.

The random effect logistic regression model can be stated as:

$$
\operatorname{logit}\left(\pi_{i j}\right)=\beta_{0}+\beta_{1} z_{j}+\beta_{2}^{\prime} x_{i j}+u_{j}
$$

where random effect $u_{j} \sim N\left(0, \sigma_{u}^{2}\right)$ and $\pi_{i j}$ was the probability that the $i^{\text {th }}$ student in the $j^{\text {th }}$ cluster was a smoker. $z_{j}$ denotes the cluster level variable (school type). $z_{j}=1$ for public schools and $z_{j}=0$ for private schools. $x_{i j}$ was a vector of the student level explanatory variables. $\beta_{1}$ was the regression parameter for the cluster level variable, $\beta_{2}$ was the vector of regression parameters corresponding to the student level variables and $\beta_{0}$ was the intercept in this model. The variance of the normally distributed random effects $\sigma_{u}^{2}$, accounts for the unaccounted heterogeneity between schools.

It was also interesting to assess if the variability between schools was different for public and private schools. The random coefficient model was stated as:

$$
\operatorname{logit}\left(\pi_{i j}\right)=\beta_{0}+\beta_{2}^{\prime} x_{i j}+u_{1 j}\left(1-z_{j}\right)+u_{2 j} z_{j}+\beta_{1} z_{j}
$$

where $u_{1 j} \sim N\left(0, \sigma_{u 1}^{2}\right)$ and $u_{2 j} \sim N\left(0, \sigma_{u 2}^{2}\right)$. Here $\sigma_{u 2}^{2}$ represents the variability between the private schools and $\sigma_{u 2}^{2}$ the variability between the public schools.

We also analyzed our data by GEE regression analysis. In our study it was reasonable to assume that correlation for any pair of students within one school would be the same; this correlation structure is referred to as "exchangeable".

We used the NLMIXED procedure in SAS version 9.2 to estimate the random effect and the random coefficient model. The SAS PROC GENMOD was used to fit the GEE model (22).

In the multivariable model we retained only those independent variables that were significant at $5 \%$ level using a likelihood ratio test. In the multivariable model interactions were also assessed. For the purpose of comparison ordinary logistic regression model was fitted including the fixed effects variable that was identified in the multivariable random effect model.

\section{Results}

In STSSP 772 male students were interviewed from both public and private schools, with a response rate of $100 \%$. Of the 772 adolescents, 431 (55.8\%) were from 15 public schools and 341 (44.1\%) were from 11 private schools. The prevalence of smoking among the public and private school male students was (18.1\%) and (8.2\%), 
respectively, and the overall prevalence among the school going male adolescents was $13.7 \%$.

The mean (SD) age in years of the students in both the public and private schools was 14.90 (SD 1.24). The range of age group for our sample population was between 10 to 16 years. The average age at which the student started smoking was 13.1 (SD 2.32) years. Our study population represented all the ethnic groups living in Pakistan. Among all those who smoked sixty-two percent of adolescents reported enjoyment as the reason for initiating smoking while $18 \%$ reported advertisements as the reason for initiation of smoking. Moreover, fifty percent smoked cigarettes by purchasing them, and $50 \%$ borrowed them from their friends.

Fit of the multivariable random effect logistic regression model, GEE, and ordinary logistic regression are reported in Table 1. The school level variable was not found to be significant (adjusted OR $=1.71$; 95\% CI: $0.70-4.26$ ) at $5 \%$ level of significance after adjusting for student's age, mother's education and parental, family and friends smoking but our data gave us the evidence that public school children were more likely to smoke. The variance of the random intercept for schools was estimated as 0.61 (standard error 0.31). The resulting chi-square test indicated that there was significant variability (p-value $<0.01$ ) between schools and there was an immense need to take between cluster variation into account for an adequate analysis. The ICC was 0.16 for the teenage smoking data.

At the individual level the results indicated that with every one year increase in age the odds of smoking increases 1.22 times after adjusting for other variables in the model (adjusted OR $=1.22$; 95\% CI: 1.01 - 1.53). Mother's education was found to have a protective effect; the risk of smoking among children whose mothers were educated was 0.51 times the risk as compared to those children whose mothers were not educated (adjusted $\mathrm{OR}=0.51 ; 95 \%$ CI 0.26 - 0.98). Parents smoking (adjusted OR $=1.78$; 95\% CI: 1.03 - 3.09) and family smoking (adjusted OR $=1.80$; 95\% CI: 1.08 - 2.97) was also found to have a significant effect on the smoking habits of adolescents attending schools. The odds of smoking among teenage males whose friends were smokers was 6.04 times relative to those whose friends were not smokers (adjusted OR = 6.04; 95\% CI; 3.63 - 10.17).

In the ordinary logistic regression model public school was significantly associated with the outcome variable. The GEE analysis provided an estimate of the working correlation as 0.04 . The random coefficient model indicate that the variability in log odds of smoking among schools was not different for public and private schools

Table 1. Comparison of results from multivariable random effect model, conventional logistic regression model, and generalized estimating equations.

\begin{tabular}{|c|c|c|c|c|c|c|c|c|c|}
\hline \multirow{2}{*}{ Variables $^{*}$} & \multicolumn{3}{|c|}{ Random Effect Model } & \multicolumn{3}{|c|}{ Ordinary Logistic Regression Model } & \multicolumn{3}{|c|}{ Generalized Estimating Equation (GEE) } \\
\hline & $\begin{array}{c}\text { B } \\
\text { coefficient }\end{array}$ & SE & $\begin{array}{c}\text { OR } \\
\text { (95\% CIs for OR) }\end{array}$ & $\begin{array}{c}\text { B } \\
\text { coefficient }\end{array}$ & SE & $\begin{array}{c}\text { OR } \\
\text { (95\% CIs for OR) }\end{array}$ & $\begin{array}{c}\text { B } \\
\text { coefficient }\end{array}$ & SE & $\begin{array}{c}\text { OR } \\
\text { (95\% CIs for OR) }\end{array}$ \\
\hline Constant & -6.32 & 1.74 & - & -5.44 & 1.68 & - & & & \\
\hline \multicolumn{10}{|c|}{ School Level Variable } \\
\hline${ }^{1}$ Public school & 0.54 & 0.43 & $1.71(0.76-4.26)$ & 0.49 & 0.25 & $1.63(1.01-1.50)$ & 0.40 & 0.34 & $1.49(0.77-2.91)$ \\
\hline \multicolumn{10}{|c|}{ Individual Level Variables } \\
\hline Age & 0.20 & 0.10 & $1.22(1.01-1.53)$ & 0.21 & 0.10 & $1.23(1.03-1.53)$ & 0.20 & 0.10 & $1.22(1.01-1.64)$ \\
\hline $\begin{array}{l}{ }^{2} \text { Mother' } \\
\text { education }\end{array}$ & -0.67 & 0.32 & $0.51(0.26-0.98)$ & -0.73 & 0.30 & $0.48(0.26-0.80)$ & -0.61 & 0.26 & $0.54(0.32-0.90)$ \\
\hline $\begin{array}{l}{ }^{3} \text { Parents } \\
\text { smoking }\end{array}$ & 0.58 & 0.26 & $1.78(1.03-3.09)$ & 0.44 & 0.23 & $1.55(0.99-2.54)$ & 0.52 & 0.24 & $1.68(1.05-2.71)$ \\
\hline $\begin{array}{l}{ }^{4} \text { Family } \\
\text { smoking }\end{array}$ & 0.59 & 0.24 & $1.80(1.08-2.97)$ & 0.52 & 0.23 & $1.68(1.07-2.66)$ & 0.54 & 0.13 & $1.71(1.30-2.72)$ \\
\hline $\begin{array}{l}{ }^{5} \text { Friend } \\
\text { smoking }\end{array}$ & 1.80 & 0.24 & $6.04(3.63-10.17)$ & 1.85 & 0.23 & $6.36(4.05-10.11)$ & 1.75 & 0.17 & $5.75(4.0-8.16)$ \\
\hline $\begin{array}{c}\sigma_{u}^{2} \\
-2 \log \\
\text { likelihood }= \\
498.4\end{array}$ & 0.61 & 0.31 & $\begin{array}{c}\text { Wald } \\
\text { p-value }=0.049\end{array}$ & \multicolumn{3}{|c|}{$-2 \log$ likelihood = 509.8} & \multicolumn{3}{|c|}{ Working correlation matrix $=0.042$} \\
\hline
\end{tabular}

Reference to: ${ }^{1}$ private school, ${ }^{2}$ illiterate, ${ }^{3}$ no parent smoking, ${ }^{4}$ no family smoking, ${ }^{5}$ no friend smoking. 
( $\mathrm{p}$-value $>0.05)$.

\section{Discussion}

Our study indicates that smoking by peers, and to a lesser extent by parents and family has a strong influence on the uptake of smoking in male adolescents attending schools in Pakistan. The estimated odds ratio for the effect of age on smoking suggests a $20 \%$ increase in the uptake of smoking with every one year increase in age.

Moreover, mother's education was a protective factor for adolescent smoking; all those adolescents whose mothers were educated were $50 \%$ less likely to smoke. These findings suggest that we need interventions that focus on educating students and families. The fact that more educated mothers have a protective influence on their adolescents' smoking habits is also an important finding when introducing smoking cessation programs.

Furthermore, having friends who smoked was found to be the most important predictor for teenage smoking. In teenage peer pressure or peers relationship becomes much stronger than family and thus adolescents are more influenced by the behavior of their friends. We would like to highlight that there is a need of some school specific smoking cessation education or intervention program in future studies.

The school level findings are interesting in the context of public health for understanding variation in teenage smoking attributable to the school environment and for developing appropriate strategies for intervention. To improve the understanding of the school effect on teenage smoking it is important to consider a multilevel analysis approach since ordinary logistic regression model does not allow for between cluster variability, and hence it underestimates the standard errors of the regression parameters and overstates the statistical significance of the variables and produces a significant association of public (versus private) school with adolescent smoking. Therefore in our study we conducted a multilevel analysis and we found significant between schools variation suggesting that the factors within certain school environments do influence children's smoking habits more than the others. Our study results were consistent with the findings from other studies [13]. School level factors therefore warrant attention, and hence there is a need to collect information at school level to understand the differences between school level factors.

The parameter estimates and standard errors for GEE models may be biased for studies with a small number of clusters ( $\mathrm{n}$ 30), especially if the clusters are severely unbalanced [14] [15]. In this study schools were considered as clusters and the size of each cluster was sufficiently large. We interviewed on an average 20 to 25 students from each school and a total of 26 schools were sampled.

There were some limitations of this study. We could not make any biomedical validation of self-reported current smoking status due to economic constraints. However studies of adolescents have shown that self-reported substance use by adolescent provides highly reliable data [16] such that accuracy of reporting may not adversely affect the quality of the outcome.

\section{Conclusion}

The education of school children with respect to the detrimental effects of smoking and influence of the school environment is one way of addressing the health of the future generation. Public health campaigns for smoking cessation should target not only the individual but also the families of adolescents attending schools.

\section{Authors Contributions}

SR: was the principle investigator of this study. This includes study conception, design, data analysis, interpretation of data and drafted the manuscript.

SM: she has made significant contribution in conception and design of the study. She has given critical feedback on analysis and the manuscript.

GL: she has contributed in conception and design of the study. She has given critical feedback on analysis and the manuscript.

NZ: she has contributed in drafting, revising and finalizing manuscript.

\section{Acknowledgements}

We acknowledge all selected Govt. and Private schools for their participation. We would like to thank study field team. I wish to express my gratitude to the Aga Khan University (AKU) for funding support. 


\section{References}

[1] WHO (2008) WHO Report on the Global Tobacco Epidemic, 2008: The MPOWER Package. WHO, Geneva.

[2] Mackay, J. and Eriksen, M. (2002) The Tobacco Atlas. Myriad Editions Limited, Brighton, UK.

[3] Media Centre (2011) Tobacco. World Health Organization. http://www.who.int/mediacentre/factsheets/fs339/en/

[4] Coalition for Tobacco Control in Pakistan (CTCPAK) (2008) New WHO Report on Global Tobacco Epidemic Calls on Nations to Implement Life Saving Tobacco Control Policies.

[5] World Health Organization (2008) Global Tobacco Epidemic. http://www.who.int/tobacco/mpower/2008/en/

[6] Sellstrom, E. and Bremberg, S. (2006) Is There a "School Effect” on Pupil Outcomes? A Review of Multilevel Studies. Journal of Epidemiology and Community Health, 60, 149-155. http://dx.doi.org/10.1136/jech.2005.036707

[7] Reid, D.J., McNeill, A.D. and Glynn, T.J. (1995) Reducing the Prevalence of Smoking in Youth in Western Countries: An International Review. Tobacco Control, 4, 266-277. http://dx.doi.org/10.1136/tc.4.3.266

[8] G. H. (2003) Multilevel Statistical Models. 3rd Edition, Hodder Arnold, London.

[9] Pokorny, S.B., Jason, L.A. and Schoeny, M. (2004) Current Smoking among Young Adolescents: Assessing School Based Contextual Norms. Tobacco Control, 13, 301-307. http://dx.doi.org/10.1136/tc.2003.005363

[10] Rozi, S., Akhtar, S., Sajid, A. and Khan, J. (2005) Prevalence and Factors Associated with Current Smoking among High School Adolescents in Karachi, Pakistan. Southeast Asian Journal of Tropical Medicine and Public Health, 36, 498.

[11] Rozi, S. and Akhtar, S. (2004) Smoking among High School Adolescents in Karachi, Pakistan. International Journal of Epidemiology, 33, 613-614. http://dx.doi.org/10.1093/ije/dyh128

[12] Lantz, P.M. (2003) Smoking on the Rise among Young Adults: Implications for Research and Policy. Tobacco Control, 12, i60-i70. http://dx.doi.org/10.1136/tc.12.suppl_1.i60

[13] Avenevoli, S. and Merikangas, K.R. (1998) Familial Influences on Adolescent Smoking. Addiction, 98, 1-20. http://dx.doi.org/10.1046/j.1360-0443.98.s1.2.x

[14] Donner, A. (1998) Some Aspects of the Design and Analysis of Cluster Randomization Trials. Journal of the Royal Statistical Society: Series C (Applied Statistics), 47, 95-113. http://dx.doi.org/10.1111/1467-9876.00100

[15] Feng, Z., McLerran, D. and Grizzle, J. (1996) A Comparison of Statistical Methods for Clustered Data Analysis with Gaussian Error. Statistics in Medicine, 15, 1793-1806. http://dx.doi.org/10.1002/(SICI)1097-0258(19960830)15:16<1793::AID-SIM332>3.0.CO;2-2

[16] Barnea, Z., Rahav, G. and Teichman, M. (1987) The Reliability and Consistency of Self-Reports on Substance Use in a Longitudinal Study. British Journal of Addiction, 82, 891-898. http://dx.doi.org/10.1111/j.1360-0443.1987.tb03909.x

\section{Submit or recommend next manuscript to SCIRP and we will provide best service for you:}

Accepting pre-submission inquiries through Email, Facebook, Linkedin, Twitter, etc

A wide selection of journals (inclusive of 9 subjects, more than 200 journals)

Providing a 24-hour high-quality service

User-friendly online submission system

Fair and swift peer-review system

Efficient typesetting and proofreading procedure

Display of the result of downloads and visits, as well as the number of cited articles

Maximum dissemination of your research work

Submit your manuscript at: http://papersubmission.scirp.org/ 